\title{
A Study on the Tolerance Band of Voltage Drop during Motor Startup for Refineries and Chemical Plants with Isolated Power Systems
}

\author{
Ho-Jeon Shin*, Man-Young Cho*, Hong-Il Chun** and Jin-Seok Kim ${ }^{\dagger}$
}

\begin{abstract}
Refineries and chemical plants with isolated power systems that have a limited power supply are more susceptible to voltage changes from disturbances compared to power systems connected with a power company. Furthermore, most loads in such cases are induction motor loads, and therefore, transient voltage characteristics when starting a high-capacity motor must be examined. In general, high-capacity motors are customized appropriately to the load performance curve by the manufacturer during the construction of an industrial plant. Subsequently, when complying with the voltage drop permitted by international standards during the design process, power supply equipment such as transformers and generators is overdesigned. Therefore, a novel analysis is necessary on standards for startup and constraint voltage drops, as well as on identifying the voltage drop limitations for starting high-capacity motors in refineries and chemical plants with isolated power systems. In this study, field tests on an industrial plant were conducted, and simulations modeled under conditions identical to those of the field test system were performed using the general-purpose program ETAP in order to compare the results.
\end{abstract}

Keywords: Isolated system, Induction motor, Inrush current, Dynamic characteristic, Voltage drop

\section{Introduction}

Recently, global refineries and chemical plants have been constructed under various conditions, and because of the environments, with regard to the storage of raw materials, stand-alone systems independent from a power company grids are being constructed at locations hundreds of kilometers away from urban areas. The sizes of such plants are diverse, ranging from a few MW to GW; these plants mostly utilize a combination of turbine-type methods as the plant's power supply. In addition, in a majority of such cases, the loads are high-capacity motors. Therefore, in order to achieve stable operation of refineries and chemical plants, it is essential to identify the configurations and operating characteristics of the plant power system, as well as to review the dynamic analysis in the design phase. Research from various aspects such as rated capacity and short-circuit capacity must be conducted for isolated power systems with a limited power supply. In particular, the special system configuration of these isolated power systems may result in unstable voltage due to limited reactive power; therefore, it has become ever more important to analyze such systems. Most cases of voltage instability are caused by the occurrence of a disturbance in existing systems connected to an infinite bus; however, in an isolated power system, the effects of reactive power can lead to a dangerous

$\uparrow$ Corresponding Author: Dept. of Electrical Engineering, Seoil University, Korea (redwolf832@gmail.com).

* Jo-Engineering, Korea. (elecsea@naver.com, cmylee@hanafos.com).

** Power Physical Basic Engineering Team, SK Engineering and Construction Co. Ltd., Korea. (terima@sk.com)

Received: January 29, 2016; Accepted: October 28, 2016 situation according to the type of load and operating characteristics, even during steady state. The main reason for voltage instability in steady state is that the isolated power system cannot provide sufficient reactive power when a load, such as the startup of a high-capacity motor, requires large reactive power [1-4].

The starting methods of high-voltage induction motors used in refineries and chemical plants include inverter start-up, direct-on-line start-up, and reactor start-up, and the size of the inrush current that occurs during the startup process differs according to the method.

Although maintaining rated voltage is important for operating an isolated power system, the bus voltage significantly decreases from the occurrence of a large voltage drop owing to the inrush current during motor startup. Furthermore, the size of the inrush current increases further when a number of motors are running at the same time and a serious voltage drop occurs as well, which affects the power quality of the peripheral loads [5-10]. A voltage drop can adversely affect the operation of the entire power system according to its size; therefore, compliance with international standards regarding the motor startup process and the size of the voltage drop at all times during the plant design process is necessary to ensure system voltage stability. However, following the design criteria based on international standards in a uniform manner during the design process may lead to overdesign when selecting the rated capacity of the power equipment, and accordingly, affordability may not be ensured because of the absence of appropriate design [11]. Furthermore, the main project participant may request greater plant capacities 
considering the margin in the capacity of the overdesigned power equipment. Therefore, it is necessary to identify the limits of the voltage drop during motor startup and conduct a novel analysis on the standards of voltage drop during both steady-state and startup processes.

For this reason, in this study, among the dynamic characteristics of the power system, the characteristics of high-capacity motor startups, which are one of the main factors affecting voltage stability, were analyzed and a new tolerance band for voltage drops during the motor startup process in refineries and chemical plants with isolated power systems was proposed. The appropriateness of the new allowed limit on voltage drop during the motor startup process was analyzed by simulation based on cases of the direct-on-line method, which is the most common starting method in refineries and chemical plants. The simulation was verified by comparing its results with those of a field test.

\section{Device Dynamic Characteristic Analysis of Induction Motor}

The equivalent model of the power system for analyzing the voltage drop during the motor startup process of an industrial plant was divided into the generation source and the load. Analysis of the generation source was conducted through a differential equation, and an algebraic equation was used for analyzing the system load [12-14].

Fig. 1 shows a simple equivalent model of an independent plant. There are various generation sources such as turbine and renewable energy sources, and although there are slight differences in the component ratio according to industrial, commercial, and residential use, the load is largely divided into static and dynamic loads, which are modeled as constant-power, constant-current, and constantimpedance loads [4].

Unlike different load characteristics, an induction motor which operates in motor startup has a various-impedance load according to the motor slip which depends on the

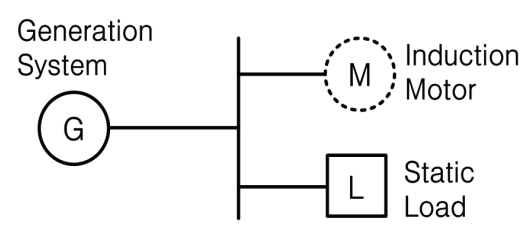

Fig. 1. Independent plant configuration

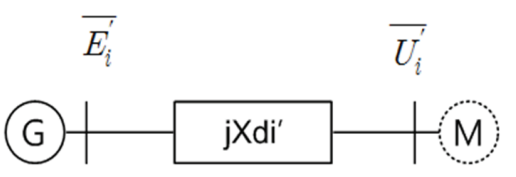

Isolated Gen System Load of Induction Motor

Fig. 2. Balanced model of generation source and load change of the reactive power. Therefore, the effects of the voltage drop in accordance with the supply capacity of the reactive power of the industrial plant during a motor startup need to be examined [15-18].

\subsection{Dynamic characteristic analysis using the reactive power capacity of the generation source}

Fig. 2 shows an overview of the power system configuration for independent industrial plants. For a steady-state drive, the majority of the load consists of the motor load $(\mathrm{M})$ for $\mathrm{m}$ number of generators $(\mathrm{G})$, and if the power system is balanced by the line impedance for each power, then it can be expressed as shown in Eqs. (1)-(4) [19].

$$
\begin{gathered}
\frac{\mathrm{d} \delta_{\mathrm{i}}}{\mathrm{dt}}=\omega_{1}-\omega_{\mathrm{i}} \\
\frac{\mathrm{d} \delta_{\mathrm{i}}}{\mathrm{dt}}=\frac{1}{\mathrm{M}_{\mathrm{i}}}\left\{\mathrm{P}_{\mathrm{mi}}-\frac{\mathrm{E}_{\mathrm{i}}^{\prime} \mathrm{U}_{\mathrm{i}}}{\mathrm{X}_{\mathrm{di}}^{\prime}} \sin \left(\delta_{\mathrm{i}}-\theta_{\mathrm{i}}\right)\right\} \\
0=\mathrm{P}_{\mathrm{i}}-\frac{\mathrm{E}_{\mathrm{i}}^{\prime} \mathrm{U}_{\mathrm{i}}}{\mathrm{X}_{\mathrm{di}}^{\prime}} \sin \left(\delta_{\mathrm{i}}-\theta_{\mathrm{i}}\right) \\
0=\frac{\mathrm{U}_{\mathrm{i}}^{2}}{\mathrm{X}_{\mathrm{di}}^{\prime}}-\frac{\mathrm{E}_{\mathrm{i}}^{\prime} \mathrm{U}_{\mathrm{i}}}{\mathrm{X}_{\mathrm{di}}^{\prime}} \sin \left(\delta_{\mathrm{i}}-\theta_{\mathrm{i}}\right)+\mathrm{Q}_{\mathrm{i}}
\end{gathered}
$$

Although $\omega$ and $\delta$ in Eqs. (1)-(4) may change according to various state variables such as auxiliary control equipment, transient stability could be neglected because the control device were analyzed characteristics on a very short transient state; therefore, the effects of control equipment are ignored. However, in a transient state caused by a voltage drop that occurs during the motor startup process, the term on the left side becomes a non-zero state. The load bus voltage $\left(\mathrm{U}_{\mathrm{i}}\right)$ changes significantly when it stabilizes in a new balance point or when it goes beyond the unstable range over the transient stability power limit, causing the generators or the motor to go out of phase. Therefore, it is necessary to examine the dynamic characteristics of the load and the generator with regard to the imbalance between the generation source and the load [19].

Large-scale industrial plants have a power system that consists of tens to hundreds of high-capacity motors, and in comparison to a unit group of induction motors, the generator's reactive power can be set as infinitely large. However, in principle, the supply limit characteristics of the generator reactive power need to be examined when reviewing the characteristics of a power system [20-21].

Fig. 3 shows the continuous operating range through the active and reactive power supply curve of the generator. The limits of the over-excitation limiter (OEL) and underexcitation limiter (UEL) of the generator were set at $90 \%$ of the generator's reactive power limit value. Furthermore, rated capacity (kVA), rated frequency, and power factor were set within $\pm 5 \%$ of the rated voltage [22]. 


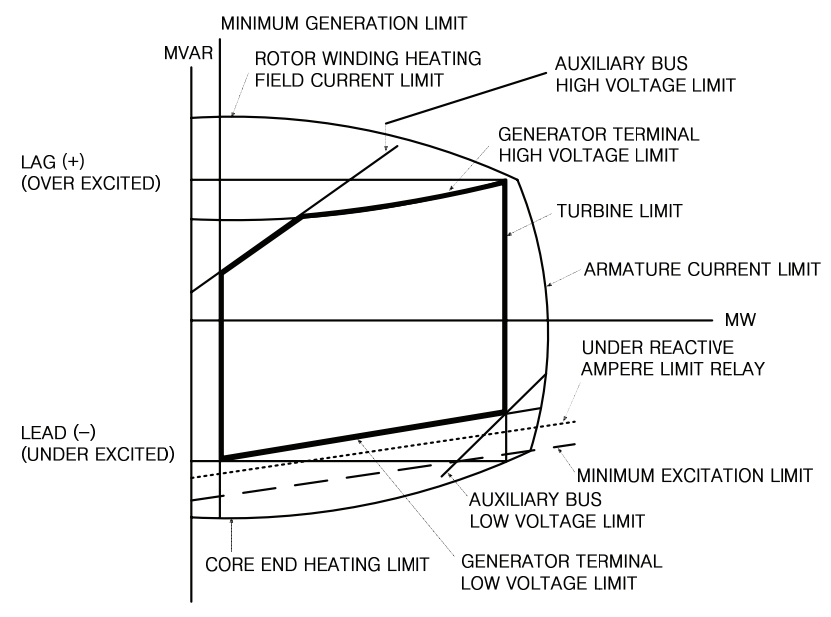

Fig. 3. Generator reactive capability limitation

Generally, the automatic voltage regulator (AVR) and the exciter $(\mathrm{EXC})$ control the terminal voltage of the generator to operate within $\pm 5 \%$ during normal operation. These relate to the insulation and operating life of a generator as well. Regarding the possible output of reactive power from a generator, the generator cannot supply the maximum reactive power output set during the design process and can produce only approximately $65 \%$ of the rated reactive power [20].

According to the $\mathrm{Q}-\mathrm{V}$ analysis during the operation of a power system, the amount of reactive power required to maintain the bus voltage is supplied by calculating the appropriate amount of reactive power for each voltage level of the busbar. Furthermore, factors such as the load shedding range to maintain the voltage or to calculate the maximum active power supply with consideration of the flow of the bus voltage and the reactive power are analyzed through the P-V analysis. The possible supply limit formula of the reactive power related to voltage can be expressed as Eqs. (5) and (6).

Eq. (5) is the formula for the output limit of the generator's reactive power that is inhibited by the exciter's current limit, and Eq. (6) is the formula for the reactive power limit of a generator limited by the armature current [20-21].

$$
\begin{gathered}
Q=\sqrt{\left(\frac{E_{m}}{X_{s}} V\right)^{2}-P^{2}}-\frac{V^{2}}{X_{s}} \\
\frac{\partial Q}{\partial V}=\frac{I_{m}^{2} V}{\sqrt{\left(I_{m} V\right)^{2}-P^{2}}}>0
\end{gathered}
$$

\subsection{Dynamic characteristic analysis of high-capacity induction motors}

\subsubsection{Issues during induction motor startup}

The startup analysis of high-capacity motors in an industrial plant is conducted prior to purchasing the motor.
In general, motors are manufactured for sufficient output in accordance with the load performance curve (pump or fan) of the analysis results. Motor startup analysis is conducted when the motor horsepower exceeds $30 \%$ of the rated capacity (kVA) of the supply transformer when there are no generators. For cases when there are only generators and no other power source, the analysis is conducted if it exceeds $10 \sim 15 \%$ of the rated capacity (kVA) of the generators according to the generator characteristics. However, because industrial plants with isolated power systems are vulnerable to voltage instability during the motor startup process, dynamic characteristic analysis of the motor is essential during the design phase, regardless of the generator's rated capacity (kVA) [11].

The effects caused in the power system during motor startup are as follows. First, a voltage drop occurs, which then affects other motors that are under normal operation. Third, a voltage problem occurs in the loads of the electronic equipment and sensitive control equipment. Fourth, if the capacity of the main generation source is small, then the voltage drops even further because of high impedance when it is installed far from the load. In this case, the voltage is raised using tools such as a voltage regulator. Fifth, for special motors, sufficient torque required for the load must be supplied in accordance with the load torque curve.

Among the various effects that occur during the motor startup process, it is important to examine the voltage drop for industrial plants with isolated power systems. In this case, the voltage drop changes according to the starting current which reaches 6-8 times the rated current for the direct-on-line method, which is typically used. The motor startup current is divided into a steady-state component and a transient component through the inrush current characteristics, and the steady-state component can be obtained using the data indicated on the motor nameplate. The transient state component can be calculated by referring to the data from the manufacturer, and calculations for each can be achieved by

$$
\begin{gathered}
\mathrm{i}_{\mathrm{l}, \mathrm{ss}}=\left|\frac{\mathrm{V}_{\mathrm{m}}}{\mathrm{Z}}\right| \sin \left(\omega \mathrm{t}-\theta_{\mathrm{z}}\right) \\
\mathrm{i}_{\mathrm{lr}, \mathrm{tr}}=\left|\frac{\mathrm{V}_{\mathrm{m}}}{\mathrm{Z}}\right| \mathrm{e}^{-\frac{\mathrm{R}}{\mathrm{L}} \mathrm{s}} \sin \left(\theta_{\mathrm{z}}\right) \\
\mathrm{i}_{\mathrm{lr}}=\left|\frac{\mathrm{V}_{\mathrm{m}}}{\mathrm{Z}}\right| \mathrm{e}^{-\frac{\mathrm{R}}{\mathrm{L}} \mathrm{t}} \sin \left(\theta_{\mathrm{z}}\right)+\left|\frac{\mathrm{V}_{\mathrm{m}}}{\mathrm{Z}}\right| \sin \left(\omega \mathrm{t}-\theta_{\mathrm{z}}\right)
\end{gathered}
$$

where $R=Z_{\text {in }} \cos \theta_{z}, L=\left(Z_{\text {in }} \sin \theta_{z}\right) /(2 \pi f), V_{m}$ is the maximum applied voltage, and $Z$ is the equivalent impedance of the circuit [26-27].

Eq. (9) is the sum of the transient and normal components, through which the inrush current can be calculated. The impedance during motor startup constructs an equivalent circuit near the short-circuit impedance and generates a large current because the impedance of the transient and normal components is very small [26-27]. 


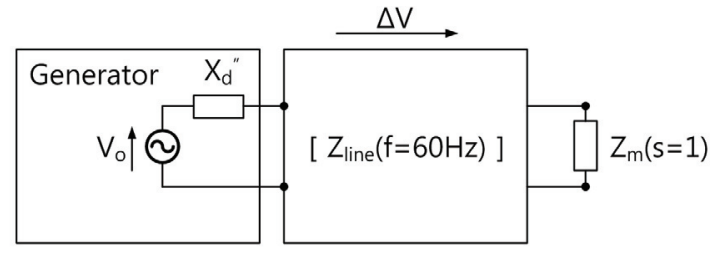

Fig. 4. Thevenin equivalent circuit for motor startup

The load in an industrial plant with an isolated power system is mostly a high-capacity motor, and a large inrush current occurs during startup, causing the bus bar of the isolated power system to experience a large voltage drop; therefore, on startup motors, the allowed terminal voltage drop should be over $80 \%$ of the rated voltage and the effect on other motors on the same bus bar requires an examination. The IEEE Std. 399-1991 limits the voltage drop for an operating motor at $71 \%$ [11].

\subsubsection{Relationship between torque and starting voltage}

The motor must be designed to accelerate the inertial load stated in the NEMA standard MG-1 as the minimum. Furthermore, regarding the "standard torque" characteristics of large-scale induction motors, NEMA requires an inertial load that can be defined as $\mathrm{WK}^{2}\left(f t-l b^{2}\right)$.

For most motors, the breakdown torque delivered in the shaft according to the prescribed operational characteristics at the rated frequency and rated voltage is twice the rated torque. As shown in Eq. (10), the torque of the motor is proportional to the square of the voltage changes. In the relationship between the voltage and the torque, the rated torque is equal at $70 \%$ of the rated voltage [24].

$$
\text { \%Torque }=V^{2} \frac{\frac{R_{r}}{s}}{\left[\left(X_{s}+X_{r}\right)^{2}+\left(R_{s}+R_{r / s}\right)^{2}\right]^{1 / 2}}
$$

Therefore, a terminal voltage of over $70 \%$ must be secured in order to obtain at least the rated torque during motor startup.

In order to obtain sufficient terminal voltage for motor startup, an equivalent circuit can be derived as shown in Fig. 4. The size of the voltage drop can be predicted through the generator's initial transient reactance $\left(X_{d}{ }_{d}\right)$, the motor impedance of the locked rotor $\left(Z_{m}\right)$, and the system impedance $\left(\mathrm{Z}_{\text {Line( } \mathrm{f}=60 \mathrm{~Hz})}\right)$, as shown in Eq. (11) [28].

$$
\Delta \text { V[p.u. }]=1-\left|\frac{\mathrm{Z}_{\mathrm{LR}}}{\mathrm{Z}_{\mathrm{LR}}+\mathrm{Z}_{\mathrm{f}=60 \mathrm{~Hz}}+\mathrm{jX}}\right|
$$

\section{Field Test and Simulation Analysis}

Field tests and simulations were conducted to analyze the allowable range of voltage drop to determine the possibility of startup during a motor startup process in an

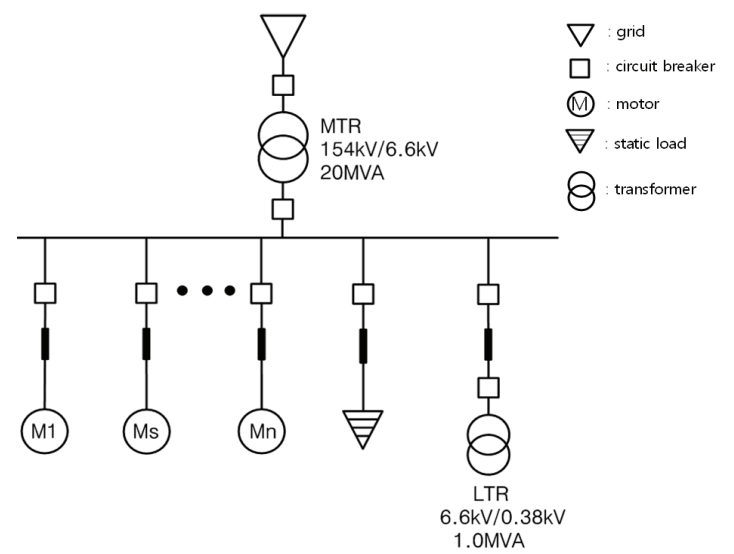

Fig. 5. Single-line diagram of the model system

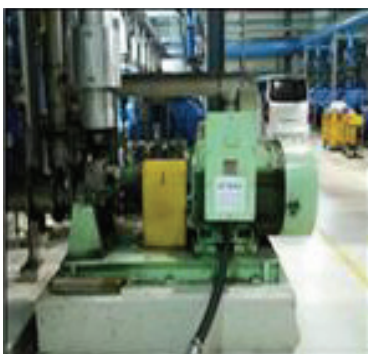

(a) Test motor

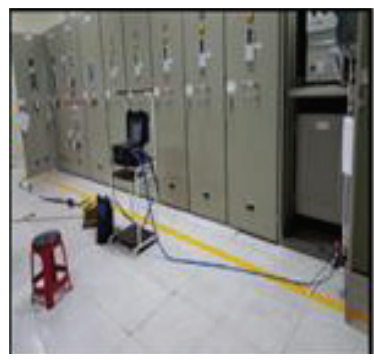

(b) Test instrumentation device
Fig. 6. Test site for motor startup

industrial plant. For the field test, it is difficult to examine the tolerance band of a voltage drop by manually adjusting the voltage in a power system of an industrial plant operating in normal state. Therefore, the voltage characteristics were tested according to the motor startup within a range that can be demonstrated. In order to analyze the tolerance band for starting status and voltage drop in accordance with the motor startup, a power system analysis simulation tool, ETAP 12.5, was used to model the power system of the field test. Fig. 5 shows the one-line diagram of the power system analyzed in field test and simulation.

Fig. 6 is a photo of the test site, showing the test motor for verifying the voltage fluctuations according to the direct-on-line method in a power system operating under normal state, as well as the configuration of the instrumentation device used for the measurement. Detailed data on the test subject motor are shown in Table 1.

Fig. 7 shows the power system configuration diagram of the ETAP simulation for examining the tolerance band of the voltage drop in situations presented through the field test, in which motor startup was difficult at various voltages. As shown in Fig. 5, multiple motors are operating while connected to the same bus bar, and a motor of $215 \mathrm{~kW}$ was configured to analyze the voltage drop during motor startup. As shown in Table 1, the test motor data applied to the simulation are identical to the motor data of the field test. 
Table 1. Direct-on-line motor data

\begin{tabular}{c|c}
\hline Items & Values \\
\hline Rated Voltage & $6.6 \mathrm{kV}$ \\
\hline Rated Current & $21.6 \mathrm{~A}$ \\
\hline Starting Current & $140.4 \mathrm{~A}$ \\
\hline Efficiency & $94.5 \%$ \\
\hline Number of Poles & 2 \\
\hline Rated Capacity & $215 \mathrm{~kW}$ \\
\hline
\end{tabular}

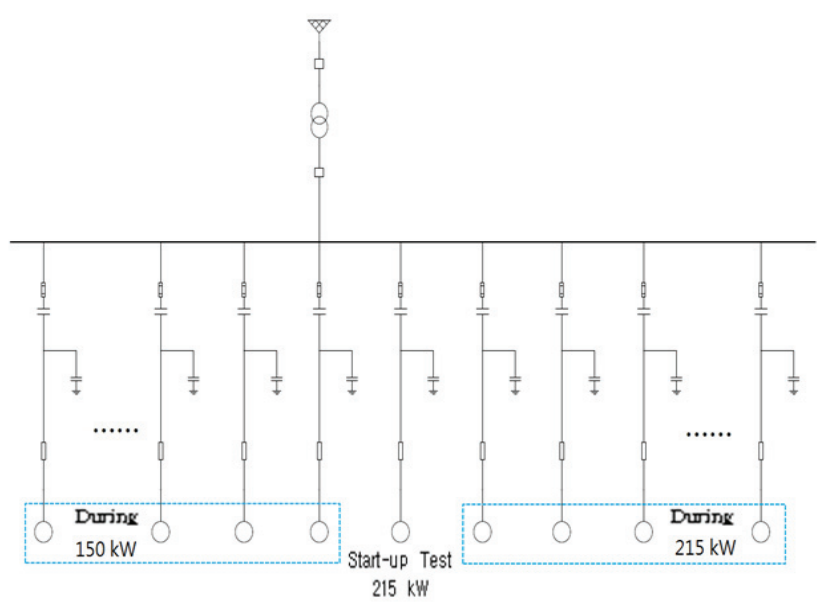

Fig. 7. ETAP simulation diagram

\subsection{Comparative analysis of the field test results and simulation results}

The field test and simulation results were analyzed to examine the tolerance band of the voltage drop that occurs in accordance with motor startup in industrial plants. Fig. 8 shows the results of the field test, in which a startup test was performed on a single $215 \mathrm{~kW}$ motor with the equipment configuration shown in Figs. 5 and 6. Prior to motor startup, the motor current was $0 \mathrm{~A}$ and the normal terminal voltage was $6.55 \mathrm{kV}$ (within the tolerance range). At this point, starting a single motor of $215 \mathrm{~kW}$ creates an inrush current (140.4A) as the starting current; this is 6.5 times the rated current (21.6A). At the same time, the motor terminal voltage experiences a voltage drop caused by the inrush current and becomes lower than the motor steady-state terminal voltage. The motor terminal voltage is reduced to $6.49 \mathrm{kV}$ by the voltage drop that occurs immediately after startup. The rated torque must be obtained for the motor to achieve the rated speed, but the torque is in proportion to the square of the voltage.

As the voltage drop becomes more severe, the motor startup time becomes longer. The terminal voltage and current of the motor reach the rated state by the rated torque when it has been achieved for approximately $3.2 \mathrm{~s}$ after the motor startup at $29.8 \mathrm{~s}$.

Fig. 9 shows the simulation analysis results of the voltage drop in motor startup. The analysis was conducted at conditions identical to those of the field test, because it is difficult to analyze this drop by manually adjusting the

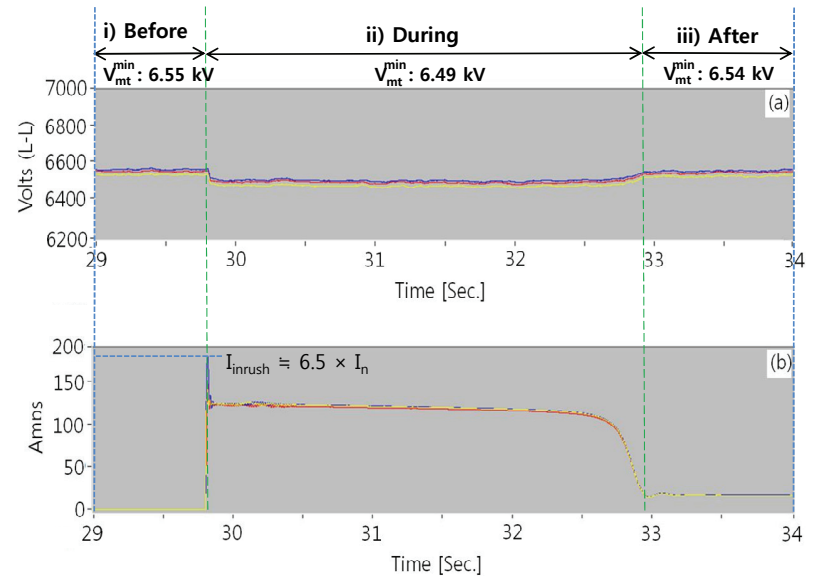

Fig. 8. Voltage and current profile of the field test results: (a) motor terminal voltage; (b) motor current

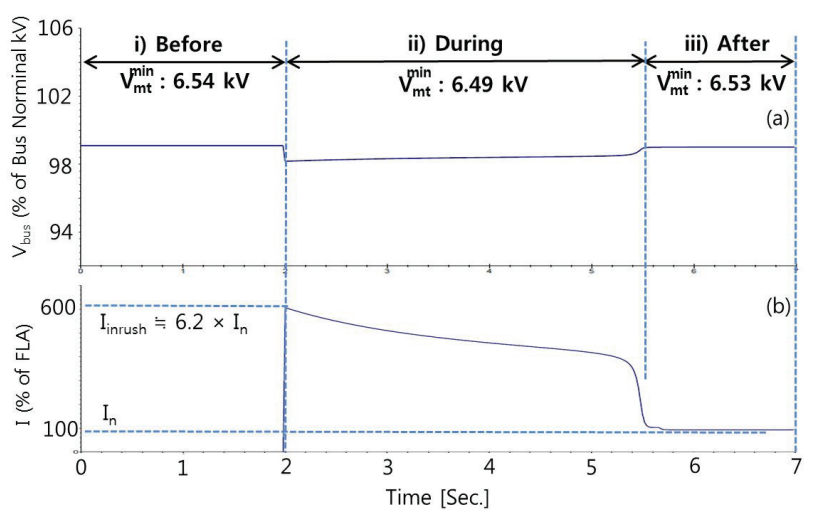

Fig. 9. Voltage and current profile by the startup simulation at $100 \%$ voltage. (a) motor terminal voltage, (b) motor current

voltage in a field test. The steady-state terminal voltage and current prior to the motor start-up were $6.54 \mathrm{kV}$ and $0 \mathrm{~A}$, respectively. The inrush current during motor startup was 6.2 times the rated current, and the terminal voltage caused by the voltage drop was $6.49 \mathrm{kV}$. In addition, the motor torque which reaches for approximately $3.4 \mathrm{~s}$ after the startup time at $2 \mathrm{~s}$ related to the voltage drop and the inrush current of indicated operating characteristics similar to those of the actual on-site motor. Afterwards, the motor reached rated state, after completing the startup process, and the simulation analysis overall presented results similar to those of the field test. Table II presents an overview of the comparison between the results of the motor startup field test and the simulation analysis.

The simulation of the field test was performed to analyze the possibility of motor startup in relation to the voltage drop that occurs in the terminal voltage due to the effects of the inrush current from the motor startup. At a minimum, the rated torque is required for starting the motor; however, this is affected by the square of the terminal voltage of the motor, and must keep adequate voltage level on the motor 
Table 2. Comparison between actual field test data and simulation results

\begin{tabular}{c|c|c|c}
\hline \multicolumn{2}{c|}{} & \multicolumn{2}{c}{ Analysis Method } \\
\cline { 3 - 4 } \multicolumn{2}{c|}{} & Field Test & Simulation \\
\hline \multirow{3}{*}{ Voltage } & Before Startup & $6.55 \mathrm{kV}$ & $6.54 \mathrm{kV}$ \\
\cline { 2 - 4 } & During Startup & $6.49 \mathrm{kV}$ & $6.49 \mathrm{kV}$ \\
\cline { 2 - 4 } & After Startup & $6.54 \mathrm{kV}$ & $6.53 \mathrm{kV}$ \\
\hline \multirow{2}{*}{ Current } & Rated & 1.0 P.U. & 1.0 P.U. \\
\cline { 2 - 4 } & Startup & 6.5 P.U. & 6.2 P.U. \\
\hline \multicolumn{2}{c}{ Startup Time } & $3.2 \mathrm{~s}$ & $3.4 \mathrm{~s}$ \\
\hline
\end{tabular}

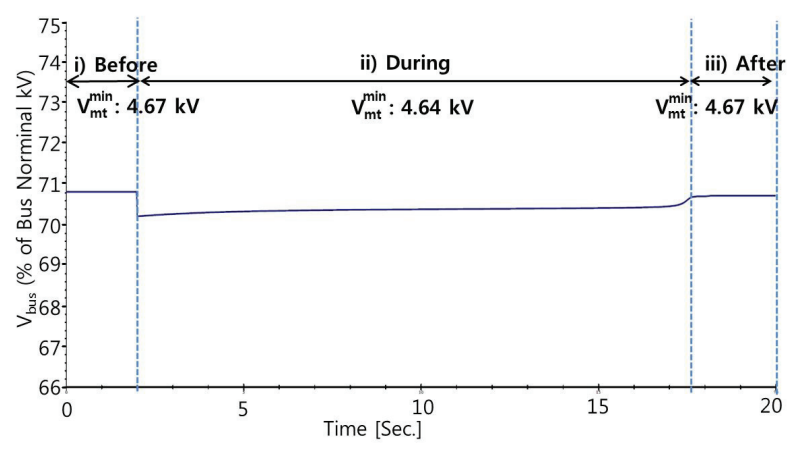

Fig. 10. Voltage profile of the startup simulation at $70.8 \%$ voltage

terminal. Therefore, it is necessary to limit the voltage drop that occurs in the motor's terminal voltage.

Fig. 10 shows the motor startup characteristics among the motor startup (section ii) results calculated by Eq. (9) when the motor's terminal voltage is $70 \%$ of the rated voltage. Although the rated voltage prior to the start-up process should show a result of $100 \%$ (i.e., $6.6 \mathrm{kV}$ ), the motor applied in this study was a small-scale motor. In order to analyze the minimum startup voltage caused by the voltage drop during the startup process due to a small impedance effect, the start-up process was started with a prior starting terminal voltage of approximately $70.8 \%$. A voltage drop occurred during motor startup resulting in a voltage of approximately $4.64 \mathrm{kV}$, which is lower than the case in which startup was reached at terminal voltage of $100 \%$. This indicates that the size of the voltage drop caused by the inrush current increases as the capacity and impedance of the motor further increase, and terminal voltage can be reduced from $100 \%$ to $70 \%$ during startup. Furthermore, it can be confirmed that an increase in the voltage drop increases the startup time of the motor, which affects the terminal voltage that in turn influences the rated torque for motor start-up.

Fig. 11 shows the motor startup characteristics when the terminal voltage prior to motor startup (section i) was reduced to $67.6 \%$ of the rated voltage to examine the tolerance band of voltage drop for possible motor startup. A voltage drop in the motor terminal voltage occurred with the startup of the same motor and a $67.1 \%$ of rated voltage was shown. Here, the startup time of the motor greatly increased in relation to the terminal voltage and torque, and

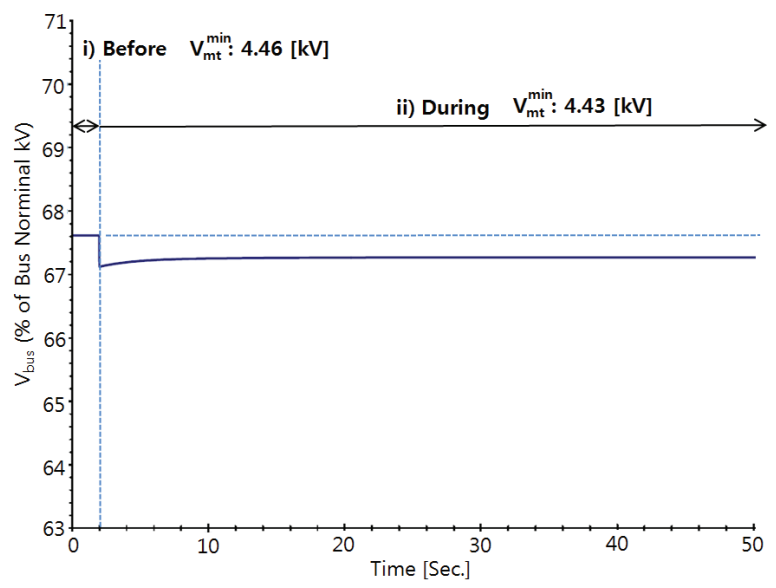

Fig. 11. Voltage profile of the startup simulation at $67.6 \%$ voltage

the motor startup was not achieved even after 50 seconds.

\subsection{Voltage drop analysis in accordance with motor startup}

The motor startup process proposed by the IEEE requires that the allowed terminal voltage drop should be over $80 \%$ of the rated voltage [11]. However, according to reference literature, a normal motor startup was achieved even with a $38 \%$ voltage drop during motor start-up [28]. Furthermore, the allowed terminal voltage during motor startup has been set at $75 \%$ for a starting torque of $100 \%$, as well as for the maximum torque condition of $200 \%$ [29].

Tens to hundreds of motors of various capacities are used in refineries and chemical plants. However, for all the motors to satisfy the voltage drop tolerance band of $80 \%$ required by the IEEE, the capacities of ancillary equipment and transformers are overdesigned, and accordingly, the capacity of the power supply generators increases as well. Therefore, the appropriate regulatory scope on the tolerance band of voltage drops during motor startup needs to be reviewed to prevent overdesigning the power system.

By examining regulations related to torques in the motor startup process and the results of field tests and simulations conducted in this study, it was confirmed that easing the tolerance band of the terminal voltage drop during the motor startup process to $70 \%$ of the rated voltage also produces appropriate motor startup results.

\section{Conclusion}

Most loads of refineries and chemical plants are motors, and tens to several hundreds of motors of various capacities are used in such cases. In the existing plant design phase, the starting characteristics of motors, along with flow and short-circuit calculations, are conducted for maintaining the motor terminal voltage at $80 \%$ of rated 
voltage in accordance with international standards. However, in this process, the capacity of the transformers and auxiliary equipment is overdesigned and the generator's capacity for supplying power increases as well.

In this study, field tests and simulations set at conditions identical to those of the field tests were conducted on industrial plants with the majority of the load of the power system composed of induction motors. Through the analysis, $70 \%$ of rated voltage was proposed for possible motor startup in consideration of the rated torque on breakdown torque regarding motor terminal voltage, even in cases with different motor capacities and impedances used at the industrial plant $[9,24,28]$.

For further research, on the basis of the proposed results, the operation of protective equipment such as an undervoltage relay (UVR) during motor startup needs to be reexamined, and additional research on power system design is needed on the expandable range of acceptable voltage drop for motor terminal voltage.

\section{References}

[1] Ian Dobson, Hsiao-Dong Chiang, James S. Thorp, Lazhar Fekih-Ahmed, "A Model of Voltage Collapse in Electric Power Systems", IEEE Proceedings, Decision and Control, vol. 3, no. pp. 2014-2109, December 1988.

[2] Carson W. Taylor, "Concepts of Under voltage Load Shedding for Voltage Stability", IEEE Trans. Power Delivery, vol. 7, no. 2, pp. 480-488, April 1992.

[3] Les Pereira, Dmitry Kosterev, Peter Mackin, Donald Davies, John Undrill, Wenchun Zhu, “An Interim Dynamic Induction Motor Model for Stability Studies in the WSCC", IEEE Trans, Power Delivery, vol. 17, no. 4, pp. 1108-1115, Nov 2002

[4] Farhad Nozari, M. David Kankam, William W. Price, "Aggregation of Induction Motors for Transient Stability Load Modeling", IEEE Trans, Power Systems, vol. PWRS-2, no. 4, pp. 1096-1103, Nov 1987.

[5] H. G. Sarmiento, E. Estrada, "A Voltage sag study in an industry with adjustable speed drives", IEEE Industry Applications Magazine, vol. 2, no. 1, pp, 1619. Jan/Feb 1996.

[6] M. McGranaghan, D. Mueller, and M. Samotyi, "Voltage Sags in Industrial Systems", IEEE Trans, Industry Applications, vol. 29, no. 2, pp. 397-403, 1993.

[7] IEEE Std. 242-2001.

[8] IEEE Std. 446-1987.

[9] Donald Reimert, "Protective relaying for power generation systems", CRC Press, 2005.

[10] Santoso, "Electrical Power Systems Quality", McGraw-Hill.

[11] IEEE Std. 399-1997: Motor starting study

[12] Brian Stott, "Power System Dynamic Response
Calculations", IEEE Proceedings, vol. 67, no. 2, pp. 219-241, Feb. 1979.

[13] P. Kunder, "Power System Stability and Control", McGraw-Hill, Inc, 1994.

[14] Kil-Young Song, "Power Engineering", Dongil press.

[15] Gyu-Seok Seo, Ji-Ho Park, Ki-Jin Kwon, "Power System Stability Analysis Considering Dynamic Loads", Journal of the Korea Academia-Industrial cooperation Society, vol. 13, no. 9, pp. 4146-4151, 2012.

[16] M. H. Kent, W. R. SCHMUS, F. A. McCRACKIN, L. M. WHEELER, "Dynamic Modeling of Loads in the Stability Studies", IEEE Trans. PAS, vol. PAS-88, no. 5, pp. 756-763, May 1969.

[17] F. lliceto, A. Ceyhan, G. Ruckstuhl, "Behavior of Loads During Voltage Dips Encountered in Stability Studies-Field and Laboratory Tests", IEEE Trans. PAS, pp. 2470-2479, Jan 1972.

[18] IEEE COMMITTEE report, "System Load DynamicsSimulation Effects and Determination of Load Constants", IEEE Trans. PAS. pp. 600-609, July 1972.

[19] Isbi Felix, "Dynamic analysis of the impact of grid connection of "La Higuera" hydropower plant to the transmission grid", Master of Science Thesis Stockholm, Sweden, 2006.

[20] M. M. Adibi, D. P. Milanicz, "Reactive Capability Limitation of Synchronous Machines", IEEE Trans. Power Systems, vol. 9, no. 1, pp. 29-40, Feb. 1994.

[21] A. E. Efthymiadis, Y. -L-I. Guo, "Generator Reactive Power Limits and Voltage Stability", IET Power System Control and Management Conference Publication, no. 421, pp. 196-199, April 1996.

[22] IEEE C57.116 - 1989, 5.1, ANSI C50.13.

[23] Gursharan Singh Grewal, Stephen Pocsai, Makhlouf M. Hakim, "Transient Motor Re-acceleration Study in an Integrated Petrochemical Facility”, IEEE Trans, Industry Applications, vol. 35, no. 4, pp. 968-977, Jul. 1999.

[24] Lubomir Sevov, A. Dave Allcock, Ray Luna, Jim Bowen, "Motor Re-acceleration to Improve Process Uptime”, IEEE Material Paper no. PCIC-2011-14, pp. $1-8,2011$.

[25] IEEE C37.96-IEEE: Guide for AC Motor Protection.

[26] Charles 1. Hubet, "Electric Machines", 2003.

[27] Jin-Seok Kim, "A Study on the Components of SFCL considering the Transient Characteristics of the Circuit Breaker in Power System", master thesis soongsil university, 2014.

[28] D. Lindenmeyer, H. W. Dommel, A. Moshref, P. Kundur, "A Framework for Black Start and Power System Restoration", IEEE Transactions on Power Systems, vol. 12, no. 1, pp. 153-157, 2000.

[29] Lubomir Sevov, Dave Allcock I Eng, Ray Luna, Jim Bowen, "Motor Reacclation to Improve Process UpTime”, IEEE PCIC, pp. 1-8, 2011. 


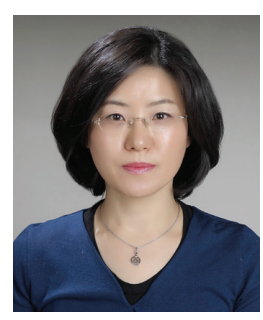

Ho-Jeon Shin She received his B.S. degree from Gyeonggi College of Science and Technology Univ. in 2005 and her M.S. and Ph.D. degrees from Soongsil Univ., Korea in 2011 and 2016, respectively. Currently, she is a Senior Technical Executive at the Joengineering Electric Power Research Institute. She's research activities cover generation and transmission technologies with special focus on grid dynamic stability analysis, high voltage power flow controllers, and electrical energy storage.

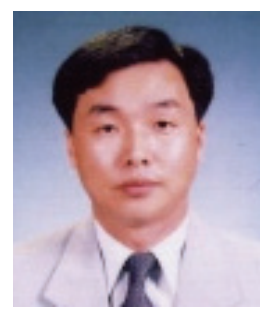

Man-Young Cho He received his M.S. and Ph.D. degrees from Soongsil Univ. in 2008 and 2013, respectively. Currently, he working as a researcher in JoEngineering. His research interests are Transmission power control, Transient surge analysis.

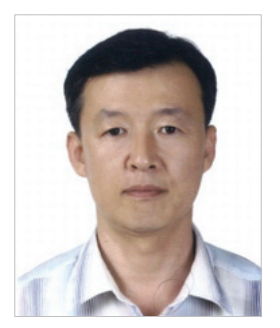

Hong-Il Chun He received his B.S. degree from Electrical Engineering at Chung-Ang Univ., respectively. Currently, he working as a researcher in SK Engineering and Construction Co. Ltd., Korea. His research interests are power control of power plant, electric grid security, signal processing.

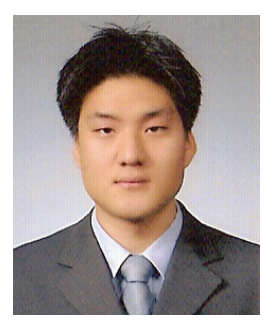

Jin-Seok Kim He received his B.S. degree from Electrical Engineering at Seoul National Univ. of Science and Technology in 2007 and his M.S. and $\mathrm{Ph} . \mathrm{D}$. degrees from Electrical Engineering at Soongsil Univ. in 2009 and 2014, respectively. Currently, he is a professor in the Dept. of Electrical Engineering at Seoil Univ. Korea. 